\title{
MULTIDISCIPLINARY DESIGN OPTIMIZATION OF A FULL VEHICLE WITH HIGH PERFORMANCE COMPUTING'
}

\author{
R. J. Yang, L. Gu, C. H. Tho \\ Ford Motor Company \\ 2101 Village Road, MD2115-SRL, Dearborn, MI 48124 \\ Phone: (313) 845-5916 \\ Email: ryang@ford.com
}

\author{
Jaroslaw Sobieszczanski-Sobieski \\ NASA Langley Research Center \\ MS 139, Hampton, VA 23681 \\ Phone: (757) 864-2799 \\ Email: j.sobieski@larc.nasa.gov
}

\begin{abstract}
Multidisciplinary design optimization (MDO) of a full vehicle under the constraints of crashworthiness, NVH (Noise, Vibration and Harshness), durability, and other performance attributes is one of the imperative goals for automotive industry. However, it is often infeasible due to the lack of computational resources, robust simulation capabilities, and efficient optimization methodologies. This paper intends to move closer towards that goal by using parallel computers for the intensive computation and combining different approximations for dissimilar analyses in the MDO process. The MDO process presented in this paper is an extension of the previous work reported by Sobieski et al. In addition to the roof crush, two full vehicle crash modes are added: full frontal impact and $50 \%$ frontal offset crash. Instead of using an adaptive polynomial response surface method, this paper employs a DOE/RSM method for exploring the design space and constructing highly nonlinear crash functions. Two MDO strategies are used and results are compared. This paper demonstrates that with high performance computing, a conventionally intractable real world full vehicle multidisciplinary optimization problem considering all performance attributes with large number of design variables become feasible.
\end{abstract}

\section{INTRODUCTION}

Continuous demands on efficient design of vehicle safety, NVH, durability, and other attribute performance have increasingly emphasized on the analysis of the vehicle structural designs as well as occupant restraint systems. Numerical computation methods have been widely employed for this purpose. The most popular and flexible computation method for vehicle design is the finite element methods (FEM). Over the past ten years, tremendous increase in computer speed and rapid evolution and development of theoretically sound, robust and efficient FEMs for the simulation of nonlinear structural dynamics have advanced computer aided vehicle design to the point where the results are trusted with a high degree of confidence.

The resulting surge in super computing is revolutionizing the way vehicles are designed. The application of crashworthiness optimization to vehicle design has drawn significant attention and interest in automotive industry over the past few years [1-6]. Recently, Yang et al. [5] developed a nonlinear response surface based safety optimization and robustness process, which has been successfully applied to the vehicle safety design. They investigated four nonlinear response surface methods for different crash modes of large-scale systems as well as occupant restraint system. Sobieski et al. [7] investigated the multidisciplinary design optimization for a car body structure under constraints of NVH and roof crush. This study extends the previous work to include two more crash modes: full frontal impact and 50\% frontal offset crash. A 512-cpu SGI Origin 2000 computer is used for computation as opposed to a $256-\mathrm{cpu}$ one as in [7]. In addition, an alternative optimization strategy is investigated to compare the results.

All the crash simulations are performed on NASA AMES SGI Origin 2000 machines: LOMAX (512 processors, $300 \mathrm{MHZ}$ ) and STEGER (256 processors, $250 \mathrm{MHZ}$ ). The nonlinear explicit finite element commercial software, RADIOSS, is used for crash simulations while MSC/NASTRAN is used to perform NVH analyses. The conservative Taylor Series approximation [8] is used to approximate the NVH performance functions.

\section{VEHICLE MODELS AND DESIGN TARGETS}

Vehicle safety design is one of the major attributes in car product development. The vehicle structure must

\footnotetext{
' Copyright 2001 by the American Institute of Aeronautics and Astronautics, Inc. All rights reserved.
} 
be designed to absorb enough crash energy through d structural deformation and attenuate the impact force to a tolerable level when crash events occur. In the real world, all crash modes need to be considered simultaneously for crash analysis and optimization. In this paper however, only full front crash impact, $50 \%$ frontal offset impact, and roof crush are considered, as the main scope of this research is to demonstrate the state-of-the-art MDO methodologies with high performance computing. In addition to the safety attributes, the vehicle NVH performance measures are also included in this study.

\section{Full Frontal Crash Model}

The full front car crash finite element model used in this study contains about 100,000 elements. It crashes into a rigid 90 degree fixed barrier with the speed of $35 \mathrm{MPH}$. The key safety performance measures in the full frontal crash include occupant Head Injury Criteria (HIC) and Chest G, which are calculated from the MADYMO analysis with importing the crash pulse from RADIOSS crash analysis. The MADYMO is a commercial multi-body occupant simulation product from TNO. The process is shown in Figure 1.

The full frontal crash is commonly used to design and validate the vehicle front structures. Federal Motor Vehicle Safety Standards 208 (FMVSS) specifies the safety regulations and test configuration. The regulation states that the HIC and Chest G injury numbers have to be within 1000 and $60 \mathrm{~g}$, respectively. The explicit finite element dynamic software RADIOSS is used to perform crash simulations throughout this study. The design targets for the full frontal impact in this study are to satisfy both FMVSS 208 regulation and corporate guidelines with occupant HIC and Chest G targeted within 450 and $45 \mathrm{~g}$, respectively. Note that the numbers may not be realistic, as they are solely used for proving this methodology. Another design requirement is the New Car Assessment Program (NCAP) star-rating criterion, proposed by the National Highway Traffic Safety Administration (NHTSA) in 1994. The NCAP star-rating criterion is derived from the total injury probability criteria combining the occupant HIC and Chest $\mathrm{G}$ numbers. The total occupant probability of severe injury is given by:

$$
\mathrm{P}_{\text {total }}=\mathrm{I}-\left(\mathrm{I}-P_{\text {head }} \mathrm{ll}-P_{\text {chest }}\right)
$$

where

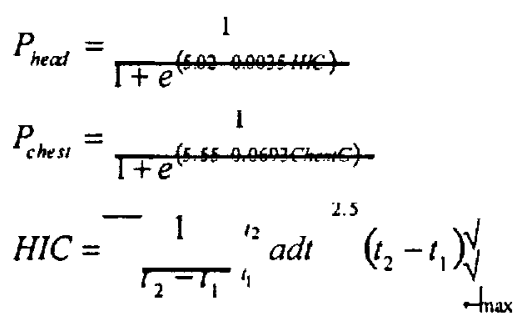

where $\quad a$ is a multiple of $\mathrm{G}^{\prime} \mathrm{s}$

$t_{1}, t_{2}$ is expressed in second and measured

\section{during impact \\ $\left(t_{2}-t_{1}\right)$ is within $36 \mathrm{~ms}$}

If the occupant $P_{\text {total }}$ is equal to or less than $10 \%$, it is graded as 5-star, which is the highest rating in NCAP star-rating, with $50 \%$ confidence interval calculated from student $t$-distribution, as shown in Figure 2. The finite element model is shown in Figure 3.

\section{Roof Crush Model}

Vehicle roof crush is a federal mandatory requirement intended to enhance passenger protection during a rollover event. The test procedure is defined in FMVSS 216. The finite element roof crush model for this study is converted from a NVH model, as shown in Figure 4.

The explicit finite element dynamic software RADIOSS is used for crush simulation. Unnecessary parts in the NVH model are deleted and some missing parts are added in the roof crush model, e.g., very detailed side doors were added and the glasses are refined. The total number of elements for roof crush is about 120,000 . A 72 inches by 30 inches rectangular ram is added to perform the roof crush as specified by the FMVSS 216. The longitudinal axis of the ram (see Figure 4) is at a forward angle (side view) of 5 degrees below the horizontal, and is parallel to the vertical plane through the vehicle's longitudinal centerline. The lateral axis is at a lateral outboard angle, in the front view projection, of 25 degrees below the horizontal. The lower surface is tangential to the surface of the vehicle and initial contact point is on the longitudinal centerline of the lower surface of the ram and 10 inches from the forward most point of the centerline. In roof crush simulation, the ram normal speed is set to be 7.5 MPH.

As described in the FMVSS 216, the force generated by vehicle resistance must be greater than $5,000 \mathrm{lbs}(22,240 \mathrm{~N})$ or 1.5 times the vehicle weight, which ever is less, through 5 inches of ram displacement. In this study, the roof crush resistant force is set to be larger than $6,000 \mathrm{lbs}(\approx 27 \mathrm{kN})$. The door thickness and material yield stresses are chosen as the design variables.

\section{0\% Frontal Offset Crash Model}

In addition to full frontal crash and roof crush, a $50 \%$ offset frontal impact mode is also considered in the optimization process. The vehicle finite element model is exactly same as the front crash model. The only difference is the barrier. In this model, the vehicle crashes into a 90 degree fixed rigid wall with $50 \%$ offset (Figure 5). The impact velocity is $40 \mathrm{mph}$. The RADIOSS is used for the simulation. The key output from the frontal offset impact is the toeboard intrusion. The design target for toeboard intrusion is set to be less than 10 inches. The design variables used for $50 \%$ 
frontal offset crash is same as those used for full front crash.

\section{NVH Model}

In car product development process, different NVH models are used for different purposes so that the quality of the NVH is high and the cost is at minimum. A car body called Body-In-Prime (BIP) is used for this study. The BIP is a trimmed body without all the closures (door, hood, deck lid) and other sub-systems (steering column, fuel tank, and seats) and trim items (carpeting, battery, etc.). A trimmed body structure may be thought of as a vehicle without the suspension and powertrain sub-systems. The BIP can also be thought as the "Body-In-White" with glass. The BIP plays an important role in determining the dynamic characteristics of the vehicle.

The BIP normal modes, static bending and static torsion analyses were conducted using the MSC/NASTRAN. The full scale NVH finite element model is shown in Figure 6 . The total number of shell elements is close to 68,000 . The total number of nodes is about 69,000 . The normal modes were calculated under the free-free condition. The static bending analysis was conduced with front ( $y z$ and $z$ ) and rear ( $x z$ and xyz) shock towers constrained while for the static torsion rear shock tower supports ( $x z$ and $x y z)$ and a mid point of the lower radiator support $(z)$ were constrained. The bending stiffness calculated using a load applied at the front rocker locations was 4,551 $\mathrm{N} / \mathrm{mm}$ while the torsion stiffness calculated using a torque applied at the front shock tower locations was $8726 \mathrm{~N}-\mathrm{m} / \mathrm{Deg}$. The free-free normal mode analysis showed that the overall torsion at $26.5 \mathrm{~Hz}$ and overall bending at $38.9 \mathrm{~Hz}$.

The torsion frequency for the BIP free-free normal mode is set to increase by $5 \%$ from 26.5 to $27.8 \mathrm{~Hz}$. The upper bounds for static torsion and static bending displacements are chosen as $3.4 \mathrm{~mm}$ and $0.9 \mathrm{~mm}$, respectively, i.e., $10 \%$ improvement from the initial design.

\section{MDO PROBLEM}

The multidisciplinary design optimization problem is to minimize the total vehicle weight subjected to design constraints of $\mathrm{NVH}$ and 3 safety crash modes: roof crush, full frontal impact, and 50\% frontal offset crash. The problem is formulated as following:

Minimize: Vehicle weight

Subject to:

NVH Constraints:

$$
2 \% .8 \mathrm{~Hz} \leq f_{3} \leq 29.3 \mathrm{~Hz}
$$

Static torsion $\leq D_{\text {, }}$

Static bending $\leq \mathrm{D}_{b}$

where $f_{3}=3^{\text {rd }}$ frequency

$\mathrm{D}_{\mathrm{\imath}}=$ displacement at local point $=3.4 \mathrm{~mm}$
$\mathrm{D}_{\mathrm{b}}=$ displacement at local point $=0.9 \mathrm{~mm}$

Reof Crush Constraints:

Crush distance $(D) \leq 5^{\prime \prime}$

Critical peak load $\left(P_{c r}\right) \geq 27 \mathrm{kN}(\approx 6000 \mathrm{lb})$

Full Frontal Impact Constraints:

Head injury criteria $\leq 450$

Chest $\mathrm{G} \leq 45 \mathrm{~g}$

$P_{\text {total }} \leq 10 \%$ (i.e. 5-star NCAP rating)

where $\quad \mathrm{P}_{\text {toal }}=$ Total probability of severe injury

50\% Frontal Offset Crash Constraints:

Toe board intrusion $\leq 10^{\prime \prime}$

In the multidisciplinary design optimization problem, there are 10 global (system) thickness design variables including windshield, roof panel, roof rail, roof cross members and pillars. The total number of design variables for the NVH model is 19 , including 10 for backlite glasses and sheet metal thickness, 9 for the stiffness of connection between the backlite glass and structures. The thickness design variables contain floor panels, jacking/towing on quarter panel, backlite glass, shotgun and radiator support. There are 5 subsystem thickness design variables for full frontal and 50\% frontal offset crash models, namely rails and subframe. As for the roof crush, 3 thickness and 7 material yield stress local design variables are taken into account for consideration.

\section{MDO PROCEDURE}

The multidisciplinary design optimization ? procedure is based on the previous work by Sobieski $e t$ al. [7], as shown in Figure 7. The difference in this paper is that instead of using an adaptive polynonial, response surface approximation, a DOE/RSM (Design of Experiments/Response Surface Method) method is employed to construct the approximation models for crash performance functions. Among the various methods for DOE and RSM, the optimal Latin Hypercube Sampling method is employed to explore ; the design space uniformly to capture the nonlinear behavior of crash functions, while the stepwise regression method is used to construct the nonlinear response surfaces based on the computer experimental points. The NVH responses are approximated by the conservative Taylor Series Approximation (TSA) as in [7].

Two optimization strategies are employed to perform the inner loop within the MDO process. The first takes advantage of the design senitivity analysis capability in MSC/NASTTRAN [7] and the second takes advantage of both the sensitivity and the optimization capabilities.

In the first strategy, the NVH sensitivities are extracted from the MSC/NASTRAN output and 
approximations are constructed using TSA. In addition to the three crash mode responses approximated by the quadratic order of stepwise regression, the MDO problem is solved by an SQP optimizer. As the NVH model is less expensive to run in this case, the NVH design variables are updated and the analysis is repeated in MCS/NASTRAN for several times ( 3 in this study) while keeping the crash approximation models unchanged. After three NVH inner loops, all design variables are updated and reflected on the NVH and crash models. Simulations are then performed to conform the results from the first MDO cycle. The crash approximation models are updated and then continue to perform the next MDO cycle if necessary. The move limits of the design variables for $\mathrm{NVH}$ approximation using the TSA are selected to be $20 \%$.

The second strategy for the inner loop optimization is to take advantage of the design optimization capabilities in MSC/NASTRAN. Instead of exporting the NVH sensitivities and performing inner optimization loop manually for three iterations, the optimization process for each MDO cycle is completed entirely in the MSC/NASTRAN by imposing the crash : performance constraints using the DEQATN and DRESP2 cards for the explicit crash equations provided from the stepwise regression approximations. The advantage of this strategy is that the inner loop can be completed without any human intervention. However, the approximated crash functions needs to be inputed explicitly.

\section{Optimal Latin Hypercube Sampling (LHS)}

In this research, the optimal Latin Hypercube Sampling method [9] is employed to explore the design space for constructing the response surfaces for crash models. The LHS is chosen due to the absence of a prior knowledge of the parametric form of the model. The experimental design is directed to minimize the bias part of the Mean Square Error (MSE) by distributing the sample points uniformly over the entire design region. The number of runs in LHS is determined by the total number of factors including control variables and noisy variables. The minimum number of runs is selected to be $3 \mathrm{~N}$ in this paper, where $\mathrm{N}$ is the total number of design variables.

\section{Stepwise Regression (SR)}

Among the various response surface methods (RSM), the stepwise regression method is used to construct the response surface functions for its simplicity and accuracy for structural crash problems [5]. The regression analysis techniques have widely been used and a detailed description of stepwise regression procedures can be found in [10]. In general, the stepwise regression model is constructed recursively by adding or deleting the independent predictions one at a time. When the model is built up, the procedure is known as forward selection. The first step is to choose one predictor, which provides the best fit. The second independent predictor to be added to the regression model is the one that provides the best fit in conjunction with the first predictor. Given the other predictors already in the model, further optimum predictors are then added at each step in a recursive fashion. Alternatively, backward elimination can be used. After certain predictors have been added in the model, the predictors are dropped one at a time. The predictor that has the least effect on the fit of the model is dropped at the stage. The stepwise regression model is built by combining the techniques of forward selection with backward elimination.

In this paper, the second order polynomial for the regression is employed to construct the nonlinear response surfaces for all crash modes (full frontal, $50 \%$ frontal offset, and roof crush) except the vehicle weight, * where a linear basis function is selected.

\section{HIGH PERFORMANCE COMPUTING}

The primary computational cost is in performing the RADIOSS finite element analysis for the sample set of design points corresponding to each of the 3 crash modes in section 2. The optimal Latin Hypercube sampling method that is used in generating an initial set of design points for frontal and offset frontal crash and the multilevel orthogonal arrays are for roof crush as in reference [7]. The computational details of the number of sample points and the elapsed computational times are provided in Table 1 . It is important to note, that the RADIOSS analysis for the baseline and sample set $\left(3^{*} N\right)$ designs can be performed concurrently on a multiprocessor machine thereby reducing the elapsed time. The two conformation analyses correspond to the verification analyses on the optimal designs obtained

Most RADIOSS crash simulations were performed on NASA Ames LOMAX machine (SGI Origin 2000, 512 processors, $300 \mathrm{MHZ}$ ). Each simulation used 4 processors. Based on numerical experience, running the crash simulation with 4 processors using RADIOSS code can achieve an approximate speedup of 3, compared to a simulation with a single processor. One cycle of the MDO process can be completed in 70 hours or approximately 3 days with the 512-cpu LOMAX computer running simultaneously. It may require 938 days to complete if it were executed on a single processor. The 938 days estimate is based on the following formula: $(46 * 60+46 * 65+25 * 70) * 3=22,500$ hours $=937.5$ days (details see Table 1). In other words, a total speedup of $321(22,500 \mathrm{hrs} / 70 \mathrm{hrs}) \mathrm{can}$ be achieved. Note that the two conformation runs are not counted, as they can only be executed after the previous MDO cycle. In Reference [7], a similar MDO problem, involving NVH and roof crush, was able to be completed in one day while it required 257 days of elapsed computing time for a complete solution on a single processor of an Origin 2000 server. Reference 
[6] reported an even better speedup using a more advanced computer and a Message Passing Interface (MPI) based version of RADIOSS.

This study shows that with high performance computing, conventional intractable vehicle design problems now become feasible.

\section{NUMERICAL RESULTS}

The initial design is started from an infeasible region, as shown in Table 2 . The constraints of the third mode frequency, torsion and bending displacements, HIC and toe-board intrusion are all violated. The design variables, their lower bounds and upper bounds are in Table 3.

After two MDO cycles, all constraints are satisfied and it is shown that the two MDO strategies yield comparable results. The total vehicle weight is reduced by $14.8 \mathrm{~kg}$ and $15.6 \mathrm{~kg}$, respectively. The objective and the maximum constraint histories are shown in Figure 8. The design histories for the two strategies are summarized in Tables 2 . The design variables for both cases are in Tables 3. The DOE results for frontal crash $\left(P_{10 \text { lal }}\right.$ vs. weight) and offset crash (maximum intrusion vs. weight) are shown in Figures 9 and 10, respectively. It is observed that significant design improvements for both strategies are achieved, after two complete cycles. In frontal crash, the $P_{\text {total }}$ (total probability of severe injury) is improved from $10 \%$ to $8.0 \%$ and $7.5 \%$, respectively. While in the offset crash, the maximum toe-board intrusion is successfully controlled within 10 inches, while reducing vehicle weight. The roof crush performance constraint is insignificant as all designs are feasible before and after the optimization process. All NVH targets are also met, i.e. improving the torsion and bending stiffness by $10 \%$ and increasing the third mode frequency by $5 \%$.

\section{CONCLUSIONS}

This research has successfully demonstrated the feasibility and benefits of the multidisciplinary design optimization methodology with high performance computing. The results showed that the MDO/HPC methodology could substantially reduce the design cycle time and vehicle weight in the development and certification of new vehicle designs while satisfying the functionality requirements.

Two optimization strategies were employed to perform the MDO process and they produced comparable results. Optimal designs were achieved with significant reduction of vehicle weight in both strategies. Apparently, more performance attributes (such as durability) and safety crash modes (such as side impact, rear impact etc.) with a larger number of design variables need to be incorporated into this process in the future to solve a real world problem.

\section{ACKNOWLEDGMENTS}

The study was performed by collaboration of the $L^{2} \dot{f}^{\prime}$ Computational AeroSciences Team of the High Performance Computing and Communication Program and Ford Research Laboratory. The authors acknowledge Mr. J. Chang of NASA Ames NAS Computing facility for his assistance. The authors would like to express their appreciation to $D$. Johnson and F. Maillet of RADIOSS Consulting Corporation for providing RADIOSS software license for crash simulation. The authors also acknowledge Drs. T. Tyan and M. Jayasuriya of Ford Motor Company for providing the crash and NVH models and consultation.

\section{REFERENCES}

1. R. J. Yang, L. Tseng, L. Nagy and J. Cheng, "Feasibility Study of Crash Optimization", ASME, Vol. 69-2, pp. 549-556, 1994.

2. M. Chargin, H. Miura, Computer Aided Engineering for Improved Vehicle Crashworthiness, Poster paper at Optimization in Industry-II, Banff, Canada, 1999.

3. N. Stander, Crashworthiness Technology Using Response Surface Methodology and Massively Parallel Programming, Poster paper at Optimization in Industry-II, Banff, Canada, 1999.

4. U. Schramm, D. Schneider and H. Thomas, "Structural Optimization in Occupant Safety and Crash Analysis", Proceedings of Conference Opticon '99: Optimization Sofware, Methods and Applications, Newport Beach, California, October 14-15, 1999.

5. R. J. Yang, L. Gu, L. Liaw, C. Gearhart, C.H. Tho, X. Liu, and B. P. Wang, "Approximations for Safety Optimization of Large Systems," Proceedings of ASME Design Engineering Technical Conferences, September, Baltimore, Maryland, 2000.

6. S. Kodiyalam, R. J. Yang, L. Gu, C. H. Tho, "Large-Scale, Multidisciplinary Optimization of a Car Body in a Scalable, High Performance Computing Environment", Submitted to ASME 2001 International Design Engineering Technical Conferences and the Computers and Information in Engineering Conference, Pittsburgh, Pennsylvania, September 9-12, 2001.

7. J. S. Sobieski, S. Kodiyalam, and R. J. Yang, "Optimization of Car Body under Constraints of Noise, Vibration, and Harshness (NVH) and Crash", AIAA, 2000-1521, April, Atlanta, GA, 2000.

8. J. H. Starnes, R. T. Haftka, Preliminary Design of Composite Wings for Buckling, Strength and Displacement Constraints, Journal of Aircraft, Vol. 16, pp. 560-570, 1979.

9. C. Currin, T. Mitchell, M. Morris, and D. Ylvisaker, "Bayesian Prediction of Deterministic Function, with Applications to the Design and 
Analysis of Computer Experiments," Journal of the American Statistical Association, Vol 86, pp. 953963.
10. P. R. Krishnaiah, "Selection of Variables under Univariate Regression Models," Handbook of Statistics, Vol. 2, 1982. 

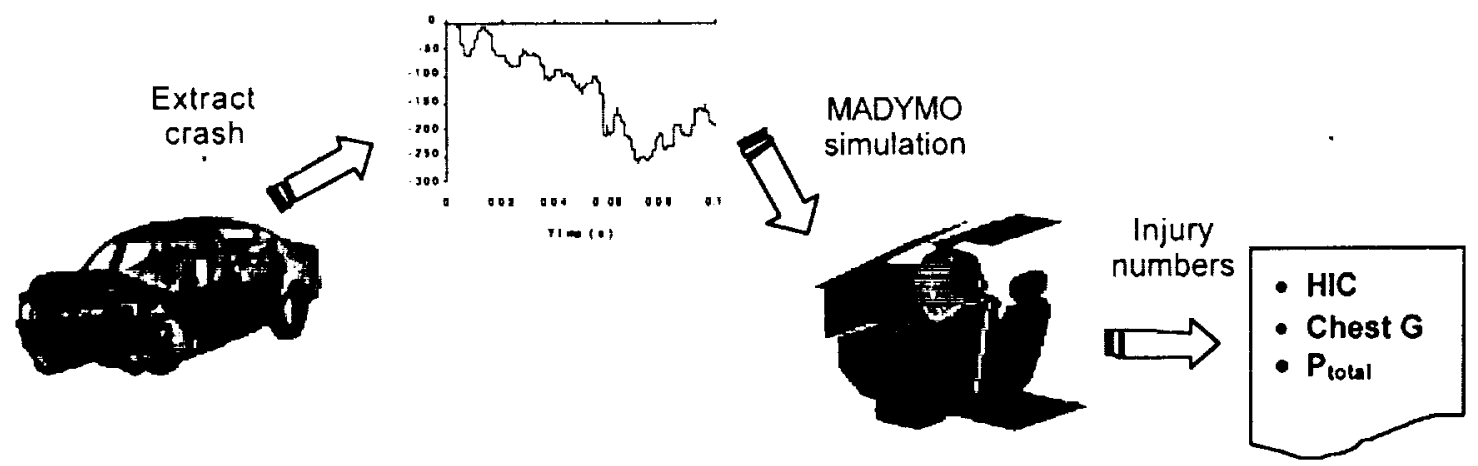

Figure 1. CAE Process for Frontal Crash Problem

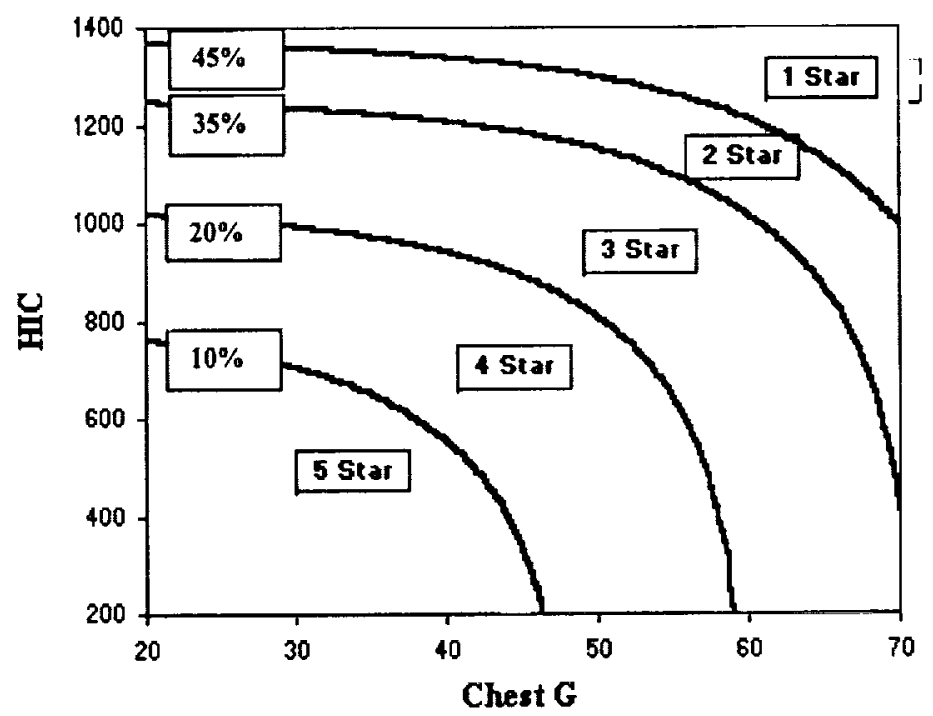

Figure 2. NCAP Star-Rating Curve

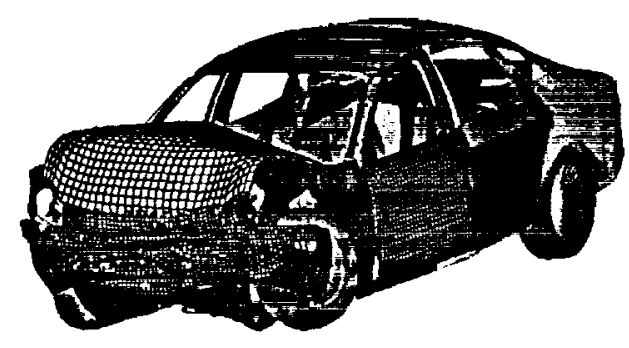

Figure 3. Frontal Crash FE Model

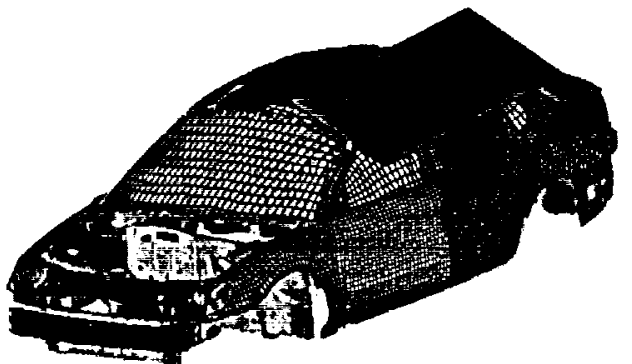

Figure 4. Roof Crush FE Model 


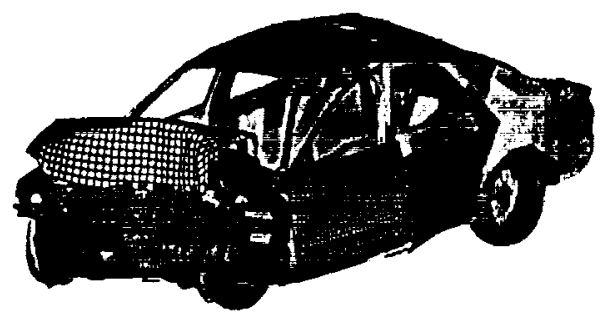

Figure 5. 50\% Frontal Offset Crash Model

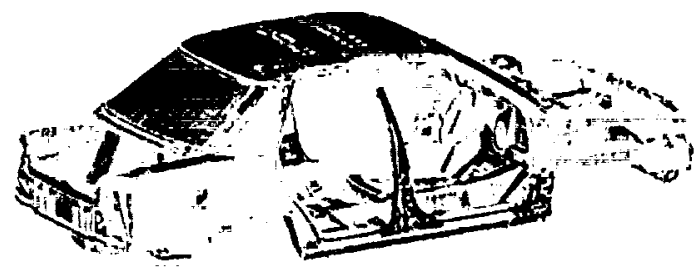

Figure 6. NVH FE Model

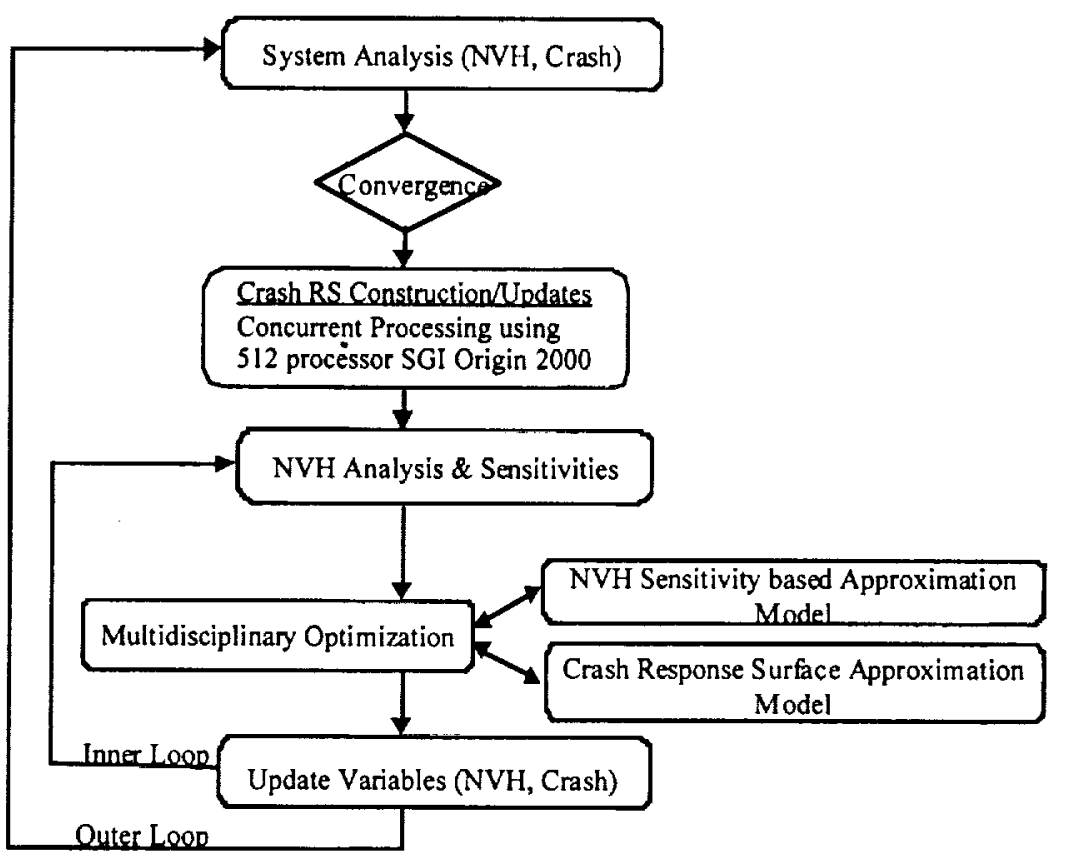

Figure 7. MDO/HPC Flow Chart

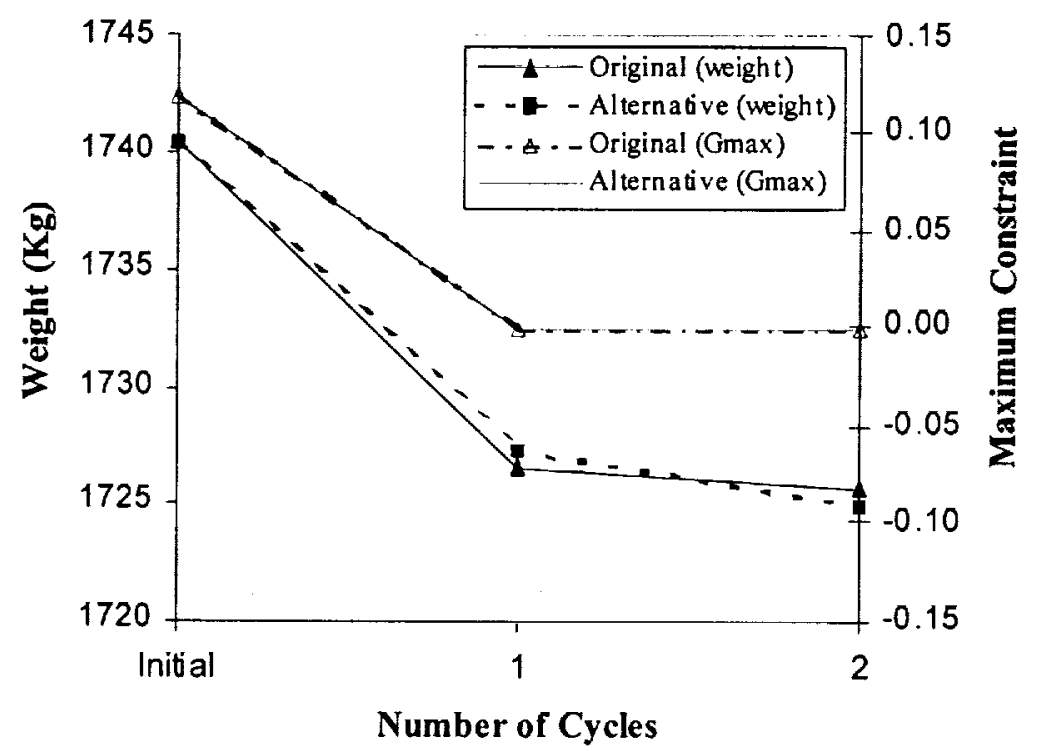

Figure 8. MDO Design History 


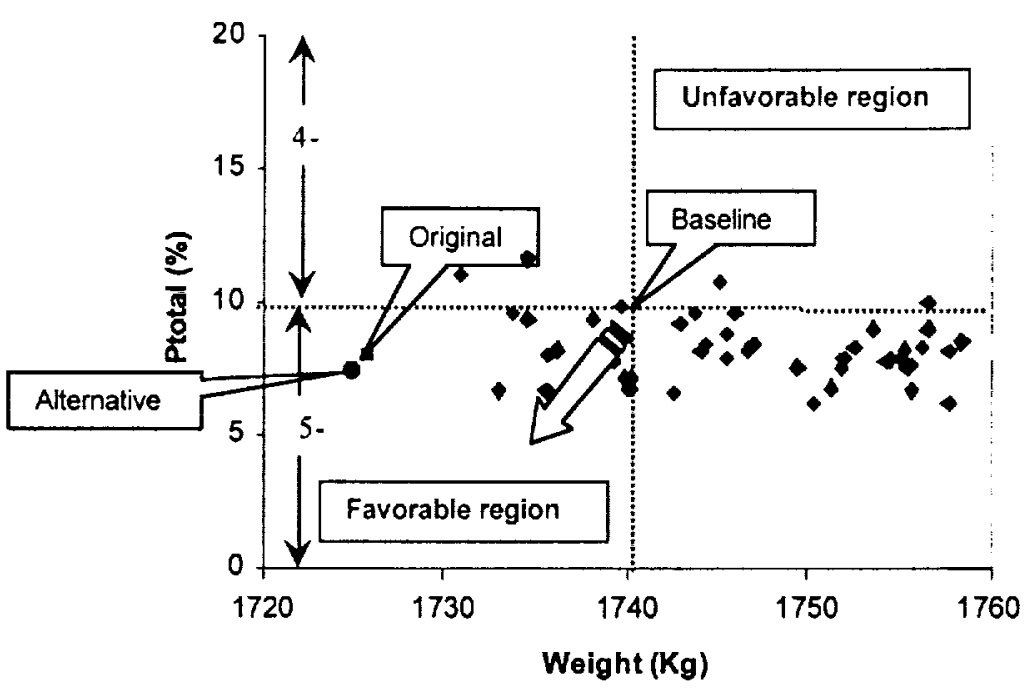

Figure 9. DOE Matrix for Frontal Crash ( $\mathrm{P}_{\text {total }}$ vs Weight)

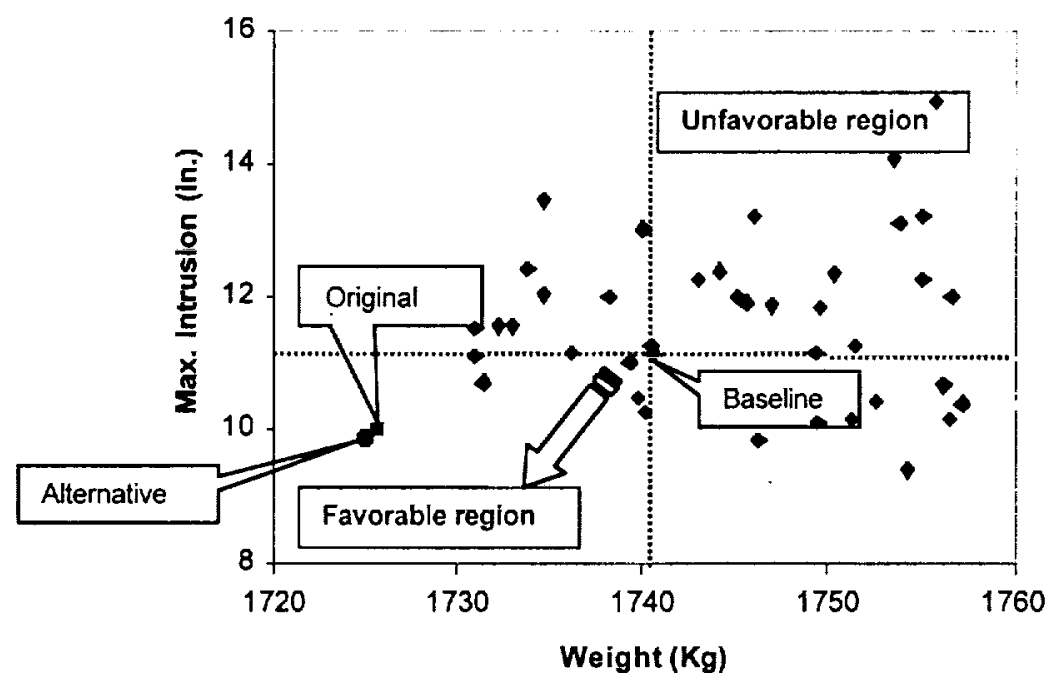

Figure 10. DOE Matrix for Offset Crash (Maximum Intrusion vs Weight) 
Table 1. Computational Requirements for Safety Disciplines

\begin{tabular}{|c|c|c|c|}
\hline Crash Modes & $\begin{array}{c}\text { Number of Design } \\
\text { Variables }(\mathrm{N})\end{array}$ & $\begin{array}{c}\text { Number of RADIOSS } \\
\text { simulations }\end{array}$ & $\begin{array}{c}\text { Total Elapsed Time } \\
\text { (using } 4 \mathrm{CPU} / \mathrm{simulation} \text { ) } \\
\text { on Origin } 2000 \text { machine }\end{array}$ \\
\hline Frontal Crash & $\begin{array}{c}10 \text { (system) }+ \\
5 \text { (local) }\end{array}$ & $\begin{array}{l}3^{*} \mathrm{~N}+1 \text { (baseline) }+ \\
2(\text { conformation })=48\end{array}$ & $60 * 48=2,880 \mathrm{hrs}$ \\
\hline Offset Crash & $\begin{array}{c}10 \text { (system) }+ \\
5 \text { (local) }\end{array}$ & $\begin{array}{l}3 * \mathrm{~N}+1 \text { (baseline) }+ \\
2(\text { conformation })=48\end{array}$ & $65 * 48=3,120 \mathrm{hrs}$ \\
\hline Roof Crush & $\begin{array}{c}10 \text { (system) }+ \\
10 \text { (local) }\end{array}$ & $\begin{array}{l}\mathrm{L} 24+1 \text { (baseline) }+ \\
2(\text { conformation })=27\end{array}$ & $70 * 27=1,890 \mathrm{hrs}$ \\
\hline Total & & & $7,890 \mathrm{hrs}$ \\
\hline
\end{tabular}

Table 2. MDO Design History

\begin{tabular}{|c|c|c|c|c|c|c|c|}
\hline \multirow[t]{2}{*}{ Attribute } & \multirow[t]{2}{*}{ Performance } & \multirow[t]{2}{*}{ Baseline } & \multirow[t]{2}{*}{ Target } & \multicolumn{2}{|c|}{ Original $^{\star}$} & \multicolumn{2}{|c|}{ Alternative $e^{\star \star}$} \\
\hline & & & & Cycle 1 & Cycle 2 & Cycle 1 & Cycle 2 \\
\hline \multirow{4}{*}{ NVH } & $3^{\text {rd }}$ frequency $(\mathrm{Hz})$ & 26.5 & $27.8 \leq f_{3} \leq 29.3$ & 29.3 & 29.3 & 27.8 & 27.8 \\
\hline & Torsion disp. $1(\mathrm{~mm})$ & 3.8 & $\leq 3.4$ & 3.4 & 3.4 & 3.4 & 3.4 \\
\hline & Torsion disp. $2(\mathrm{~mm})$ & -3.8 & $\geq-3.4$ & -3.4 & -3.4 & -3.4 & -3.4 \\
\hline & Bending disp. (mm) & -0.97 & $\geq-0.9$ & -0.9 & -0.87 & -0.9 & -0.9 \\
\hline \multirow{3}{*}{ Frontal } & $\mathrm{HIC}$ & 500 & $\leq 450$ & 356 & 411 & 411 & 357 \\
\hline & Chest G & 42 & $\leq 45$ & 38 & 39 & 42 & 39 \\
\hline & $P_{\text {total }}(\%)$ & 10 & $\leq 10$ & 7.3 & 8.0 & 9.2 & 7.5 \\
\hline Roof & Resistance force $(\mathrm{kN})$ & 34.7 & $\geq 27$ & 30.5 & 31.2 & 31.4 & 31.3 \\
\hline \multirow{5}{*}{ Offset } & Intrusion 1 (in.) & 11.2 & $\leq 10$ & 9.7 & 9.9 & 10 & 9.9 \\
\hline & Intrusion 2 (in.) & 10.8 & $\leq 10$ & 9.4 & 10 & 9.7 & 9.8 \\
\hline & Intrusion 3 (in.) & 10.9 & $\leq 10$ & 9.4 & 10 & 10 & 9.8 \\
\hline & Intrusion 4 (in.) & 10.1 & $\leq 10$ & 8.9 & 9.4 & 9.5 & 9.4 \\
\hline & Intrusion 5 (in.) & 10.5 & $\leq 10$ & 9.3 & 9.8 & 9.9 & 9.6 \\
\hline 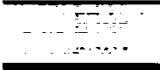 & Weight $(\mathrm{Kg})$ & 1740.5 & Minimize & 1726.6 & 1725.7 & 1727.2 & 1724.9 \\
\hline
\end{tabular}


Table 3. MDO Design Variables

\begin{tabular}{|c|c|c|c|c|c|c|c|c|}
\hline \multirow[t]{3}{*}{ No. } & \multirow[t]{2}{*}{ Design Variable } & \multirow{2}{*}{$\begin{array}{l}\text { Initial } \\
\text { Design }\end{array}$} & \multirow{2}{*}{$\begin{array}{l}\text { Lower } \\
\text { Bound }\end{array}$} & \multirow{2}{*}{$\begin{array}{l}\text { Upper } \\
\text { Bound }\end{array}$} & \multicolumn{2}{|c|}{ Original* } & \multicolumn{2}{|c|}{ Alternative** } \\
\hline & & & & & Cycle 1 & Cycle 2 & Cycle 1 & Cycle 2 \\
\hline & 7 & \multicolumn{4}{|c|}{$=$ Common Design Variables (10) } & \multicolumn{3}{|c|}{ 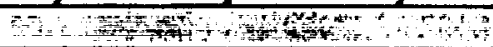 } \\
\hline $\mathrm{T}$ & Windshield & 3.8 & 2.6 & 5.0 & $2.6 \downarrow$ & $2.6 \downarrow$ & $2.6 \downarrow$ & $2.6 \downarrow$ \\
\hline 2 & Roof panel & 0.7 & 0.6 & 1.5 & $0.6 \downarrow$ & $0.6 \downarrow$ & $0.6 \downarrow$ & $0.6 \downarrow$ \\
\hline 3 & Roof rail & 1.0 & 0.6 & 1.5 & $0.6 \downarrow$ & $0.6 \downarrow$ & $1.16 \uparrow$ & $0.73 \downarrow$ \\
\hline 4 & Roof cross member (fr) & 1.0 & 0.6 & 1.5 & $0.6 \downarrow$ & $0.6 \downarrow$ & $0.88 \downarrow$ & $0.6 \downarrow$ \\
\hline 5 & Roof cross member ( $\mathrm{rr}$ ) & 0.9 & 0.6 & 1.5 & $0.6 \downarrow$ & $0.6 \downarrow$ & $0.7 \downarrow$ & $0.6 \downarrow$ \\
\hline 6 & A-Pillar & 0.8 & 0.6 & 1.5 & $1.11 \uparrow$ & $0.94 \uparrow$ & $0.92 \uparrow$ & $0.99 \uparrow$ \\
\hline 7 & B-Pillar 1 & 1.0 & 0.6 & 1.5 & $0.77 \downarrow$ & $0.6 \downarrow$ & $1.2 \uparrow$ & $1.5 \uparrow$ \\
\hline 8 & B-Pillar 2 & 0.8 & 0.6 & 1.5 & $0.61 \downarrow$ & $0.6 \downarrow$ & $0.96 \uparrow$ & $1.2 \uparrow$ \\
\hline 9 & B-Pillar 3 & 1.35 & 1.0 & 2.0 & $1.04 \downarrow$ & $1.0 \downarrow$ & $1.56 \uparrow$ & $1.8 \uparrow$ \\
\hline 10 & C-Pillar & 0.8 & 0.6 & 1.5 & $0.6 \downarrow$ & $0.6 \downarrow$ & $0.94 \uparrow$ & $0.6 \downarrow$ \\
\hline \multicolumn{9}{|c|}{ 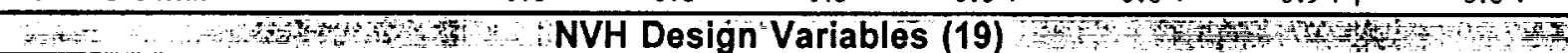 } \\
\hline 11 & Rear floor panel & 0.76 & 0.5 & 1.0 & $1.0 \uparrow$ & $1.0 \uparrow$ & $0.99 \uparrow$ & $1.0 \uparrow$ \\
\hline 12 & $\begin{array}{l}\text { Rear floor cross } \\
\text { member }\end{array}$ & 1.4 & 0.8 & 2.0 & $1.87 \uparrow$ & $2.0 \uparrow$ & $1.62 \uparrow$ & 1.4 \\
\hline 13 & Front floor pan & 0.76 & 0.5 & 1.0 & $0.58 \downarrow$ & $0.5 \downarrow$ & $0.5 \downarrow$ & $0.5 \downarrow$ \\
\hline 14 & Front floor inner & 1.07 & 0.5 & 1.5 & $1.27 \uparrow$ & $1.32 \uparrow$ & $1.17 \uparrow$ & $1.16 \uparrow$ \\
\hline 15 & Jacking/towing & 0.8 & 0.5 & 1.5 & $1.38 \uparrow$ & $1.5 \uparrow$ & $0.98 \uparrow$ & $1.5 \uparrow$ \\
\hline 16 & Quarter panel & 0.8 & 0.5 & 1.5 & $0.9 \uparrow$ & $0.9 \uparrow$ & $0.85 \uparrow$ & $0.84 \uparrow$ \\
\hline 17 & Backlite glass & 3.8 & 2.6 & 5.0 & $2.6 \downarrow$ & $2.6 \downarrow$ & $2.8 \downarrow$ & $2.6 \downarrow$ \\
\hline 18 & Rear tire cover & 0.75 & 0.5 & 1.0 & $1.0 \uparrow$ & $1.0 \uparrow$ & $0.86 \uparrow$ & $0.9 \uparrow$ \\
\hline 19 & Shotgun & 1.22 & 0.9 & 1.5 & $1.1 \downarrow$ & $1.5 \uparrow$ & $1.32 \uparrow$ & $0.99 \uparrow$ \\
\hline 20 & Radiator support & 0.76 & 0.5 & 1.0 & $0.58 \downarrow$ & $0.5 \downarrow$ & 0.76 & $0.5 \downarrow$ \\
\hline 21 & Top edge (x-comp) & 1073 & 750 & 1395 & 1073 & 1073 & $1074 \uparrow$ & $1074 \uparrow$ \\
\hline 22 & Top edge (y-comp) & 367 & 256 & 478 & 368 & 368 & 388.9 & $401.1 \uparrow$ \\
\hline 23 & Top edge (z-comp) & 2734 & 1912 & 3554 & 2734 & 2734 & 2734 & 2734 \\
\hline 24 & Bottom edge (x-comp) & 1424 & 1000 & 1850 & 1424 & 1424 & 1424 & 1424 \\
\hline 25 & Bottom edge (y-comp) & 487 & 340 & 630 & 487 & 487 & 487 & 487 \\
\hline 26 & Bottom edge (z-comp) & 3628 & 2540 & 5090 & 3628 & 3628 & 3628 & 3628 \\
\hline 27 & Side edges $(\mathrm{x}$-comp & 1521 & 1065 & 1977 & 1521 & 1521 & 1521 & 1522 \\
\hline 28 & Side edges (y-comp) & 520 & 365 & 675 & 520 & 520 & $522 \uparrow$ & $523 \uparrow$ \\
\hline 29 & Side edges (z-comp) & 3874 & 2710 & 5035 & 3874 & 3874 & 3874 & 3874 \\
\hline \multicolumn{9}{|c|}{ 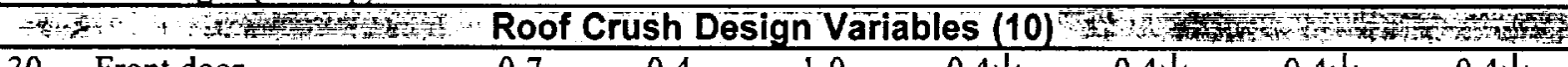 } \\
\hline 30 & Front door & 0.7 & 0.4 & 1.0 & $0.4 \downarrow$ & $0.4 \downarrow$ & $0.4 \downarrow$ & $0.4 \downarrow$ \\
\hline 31 & Front door inner & 0.7 & 0.4 & 1.0 & $0.4 \downarrow$ & $0.4 \downarrow$ & $0.4 \downarrow$ & $0.4 \downarrow$ \\
\hline 32 & Rear door & 1.0 & 0.7 & 1.3 & $0.77 \downarrow$ & $0.7 \downarrow$ & $0.7 \downarrow$ & $0.7 \downarrow$ \\
\hline 33 & Material for A-Pillar 1 & 0.207 & 0.192 & 0.345 & 0.207 & 0.207 & 0.207 & 0.207 \\
\hline 34 & Material for A-Pillar 2 & 0.207 & 0.192 & 0.345 & 0.207 & 0.207 & 0.207 & 0.207 \\
\hline 35 & Material for A-Pillar 3 & 0.207 & 0.192 & 0.345 & 0.207 & 0.207 & 0.207 & 0.207 \\
\hline 36 & Material for B-Pillar 1 & 0.207 & 0.192 & 0.345 & 0.207 & 0.207 & 0.207 & 0.207 \\
\hline 37 & Material for B-Pillar 2 & 0.207 & 0.192 & 0.345 & 0.207 & 0.207 & 0.207 & 0.207 \\
\hline 38 & Material for fr. door 1 & 0.207 & 0.192 & 0.345 & 0.207 & 0.207 & 0.207 & 0.207 \\
\hline 39 & Material for fr. door 2 & 0.207 & 0.192 & 0.345 & 0.207 & 0.207 & 0.207 & 0.207 \\
\hline \multicolumn{9}{|c|}{ Frontal Crash and 50\% Frontal Offset Crash Design Variables (5) } \\
\hline 40 & Subframe & 2.0 & 1.0 & 3.0 & $1.0 \downarrow$ & $1.0 \downarrow$ & $1.0 \downarrow$ & $1.0 \downarrow$ \\
\hline 41 & Rail 1 & 1.9 & 1.0 & 3.0 & $1.0 \downarrow$ & $1.0 \downarrow$ & $1.0 \downarrow$ & $1.0 \downarrow$ \\
\hline 42 & Rail 2 & 1.9 & 1.0 & 3.0 & $1.0 \downarrow$ & $1.0 \downarrow$ & $1.0 \downarrow$ & $1.0 \downarrow$ \\
\hline 43 & Rail 3 & 1.9 & 1.0 & 3.0 & $1.0 \downarrow$ & $1.0 \downarrow$ & $1.0 \downarrow$ & $1.0 \downarrow$ \\
\hline 44 & Rail 4 & 2.4 & 1.0 & 3.0 & $2.04 \downarrow$ & $2.11 \downarrow$ & $2.05 \downarrow$ & $1.99 \downarrow$ \\
\hline
\end{tabular}




\section{Prediction of HSPPO Evaluation Cost}

References:

1. Plassman, G. E., Su, P. S., Computer Sciences Corporation, and Spengler, W. E., COMSO, "A Test Function Suite with Benchmark Solutions for Unconstrained Optimization", December, 2000

2. Plassman, G. E. and Sreekantamurthy, T., "A Contouring Method for Statistical Interpretation of Performance Data for a Stochastic DOE Based Parallel Optimizer", January, 2001

Attachments:

Plots of predicted benchmark cost in elapsed time for serial and ideal parallel exeution on an SGI Origin 2000 computer, where parallel times presume the number of processors, NP = NX.

\section{Observations}

The evaluation counts and corresponding elapsed (single processor) times for the suite of benchmark functions in appendix $B$ of above Reference 1 were used to predict function evaluation only costs expected when evaluating HSPPO according to the plan addressed in above Reference 2 . This plan anticipates computing the number of function evaluations, NS, given below for the various planned solution of each of the problems of the test suite.

$\mathrm{NS}=(1+\mathrm{NX}) 2^{5} 2^{\mathrm{k}}, \mathrm{k}=0,9$

For each benchmark function a total of $25 * 10 * 6$ solutions would be computed, representing 25 replications of problems over 10 levels of NS $(k=0,9)$, where each level is solved by 6 levels of HSPPO iteration, NI. Since the value of NS doubles for each higher level, the NS cost for all levels is bounded above by twice the value of NS for the highest level. The following predictions are based on this bound. That is the predicted cost of all $25^{*} 10^{*} 6$ solutions of each benchmark is based on $25^{*} 6 * 2$ times the cost of a single solution employing the highest level of NS.

Cost for all 30 benchmarks by NX and over all NX through 64 (total)

\begin{tabular}{|r|r|r|r|r|r|r|r|}
\hline NX & 2 & 4 & 8 & 16 & 32 & 64 & Total \\
\hline $\begin{array}{r}\text { Single } \\
\text { CPU } \\
\text { Hours }\end{array}$ & 1.454172 & 2.843939 & 10.92589 & 64.74165 & 456.0479 & 3496.68 & 4032.693 \\
\hline
\end{tabular}

Cost for all 23 benchmarks, with Order NX Complexity, by NX and over all NX through 64 (total)

\begin{tabular}{|r|r|r|r|r|r|r|r|}
\hline NX & 2 & 4 & 8 & 16 & 32 & 64 & Total \\
\hline $\begin{array}{r}\text { Single } \\
\text { CPU } \\
\text { Hours }\end{array}$ & 0.939142 & 1.72799 & 3.724177 & 9.652021 & 29.73078 & 99.10535 & 144.8795 \\
\hline
\end{tabular}

The available budget on the NAS Origin 2000 for this fiscal year is 7500 single CPU hours. Given the above estimates, we may want to eliminate general testing of benchmarks whose complexity is nonlinear (in our case quadratic) in NX. We could consider running all benchmarks through $\mathrm{NX}=16$. We could also consider using fewer data points, that is fewer levels of HSPPO iterations, NI, or levels of allowed function 
evaluations, NS. The addressed evaluation plan anticipates the required NS for effective HSPPO solutions will increase in approximate linear fashion with NX. This may not prove true.

in $)^{l}$

$\checkmark I_{1}$

With our present evaluation plan, we run six tests, with varying levels of HSPPO iterations, for each subset of HSPPO tests addressing a fixed combination of benchmark problem, design space dimension, NX, and level of allowed function evaluations, NS. This is desirable for at least some tests to determine optimal algorithm performance characteristics. However, it may well not be necessary for all problems or all problem sizes. Once an optimal NI is determined, or its variation over different benchmarks and size of NX understood, the cost of further tests could be reduced by a factor of six (6).

Note that the average execution cost of benchmarks of linear complexity in NX increases in an approximate linear fashion only for relatively small NX. For NX $>8$ the cost increase is greater than linear in $\mathbf{N X}$.

Test for problems of dimension NX $>64$ will need to be very selective to manage resources. The following table provides cost predictions for the cheapest (Hyper-Ellipsoid, \#2) and the most expensive (Michalewicz, M=10, \#21) of the benchmarks which are linear with respect to NX in cost.

Cost in Single CPU Hours for Full Testing of Two Order NX Complexity Benchmarks for NX up to 1024

\begin{tabular}{|c|c|c|}
\hline NX or Total & Hyper-Ellipsoid, \#2 (cheap) & Michalewicz, M=10, \#21 (costly) \\
\hline 2 & 0.030786 & 0.054047 \\
\hline 4 & 0.051484 & 0.11369 \\
\hline 8 & 0.09468 & 0.302844 \\
\hline 16 & 0.187218 & 0.964163 \\
\hline 32 & 0.40406 & 3.385943 \\
\hline 64 & 0.972902 & 12.62922 \\
\hline 128 & 2.695735 & 48.82744 \\
\hline 256 & 8.031792 & 192.4867 \\
\hline 512 & 27.37219 & 760.771 \\
\hline 1024 & 99.55476 & 3034.576 \\
\hline Total & 139.3956 & 4054.111 \\
\hline
\end{tabular}



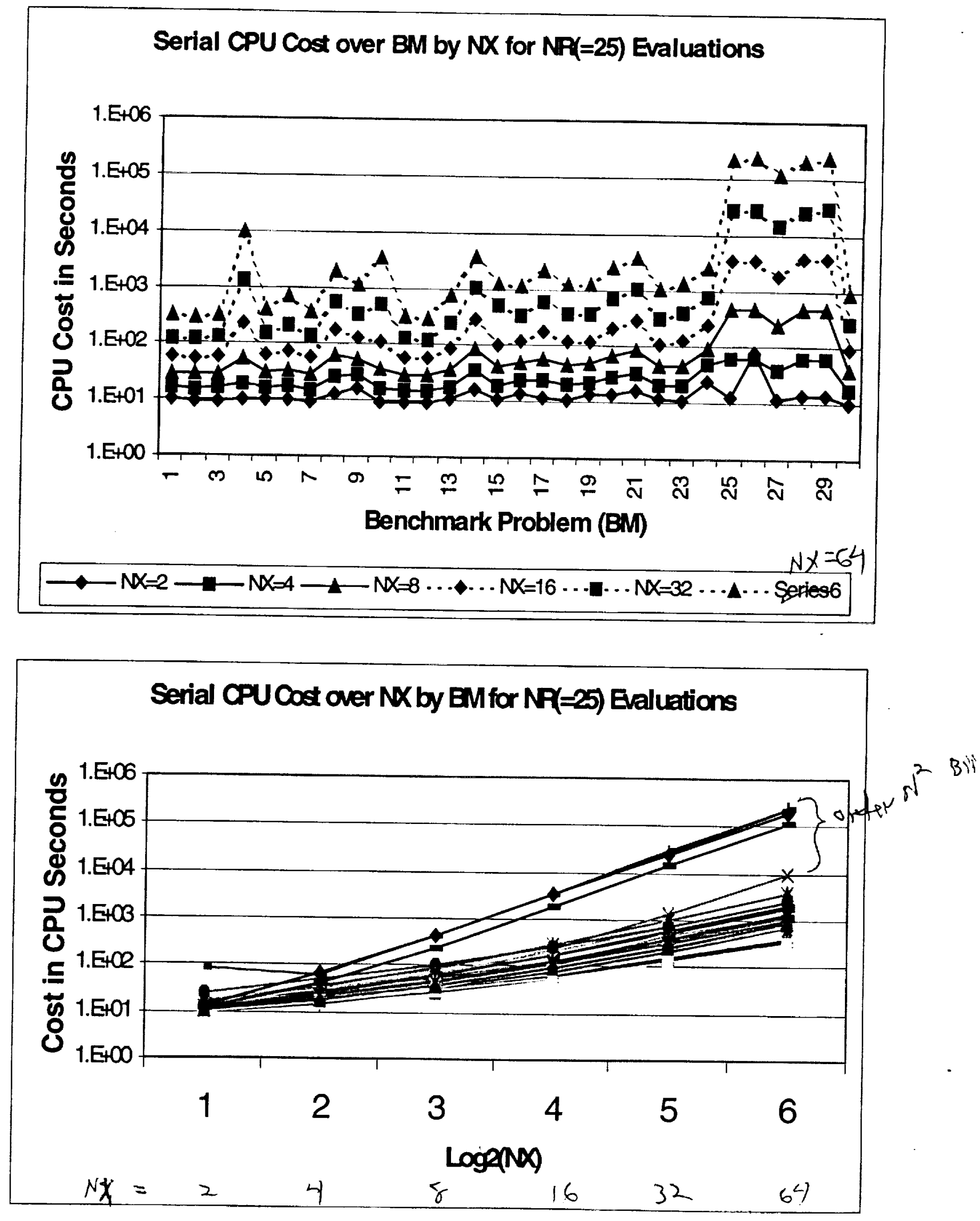

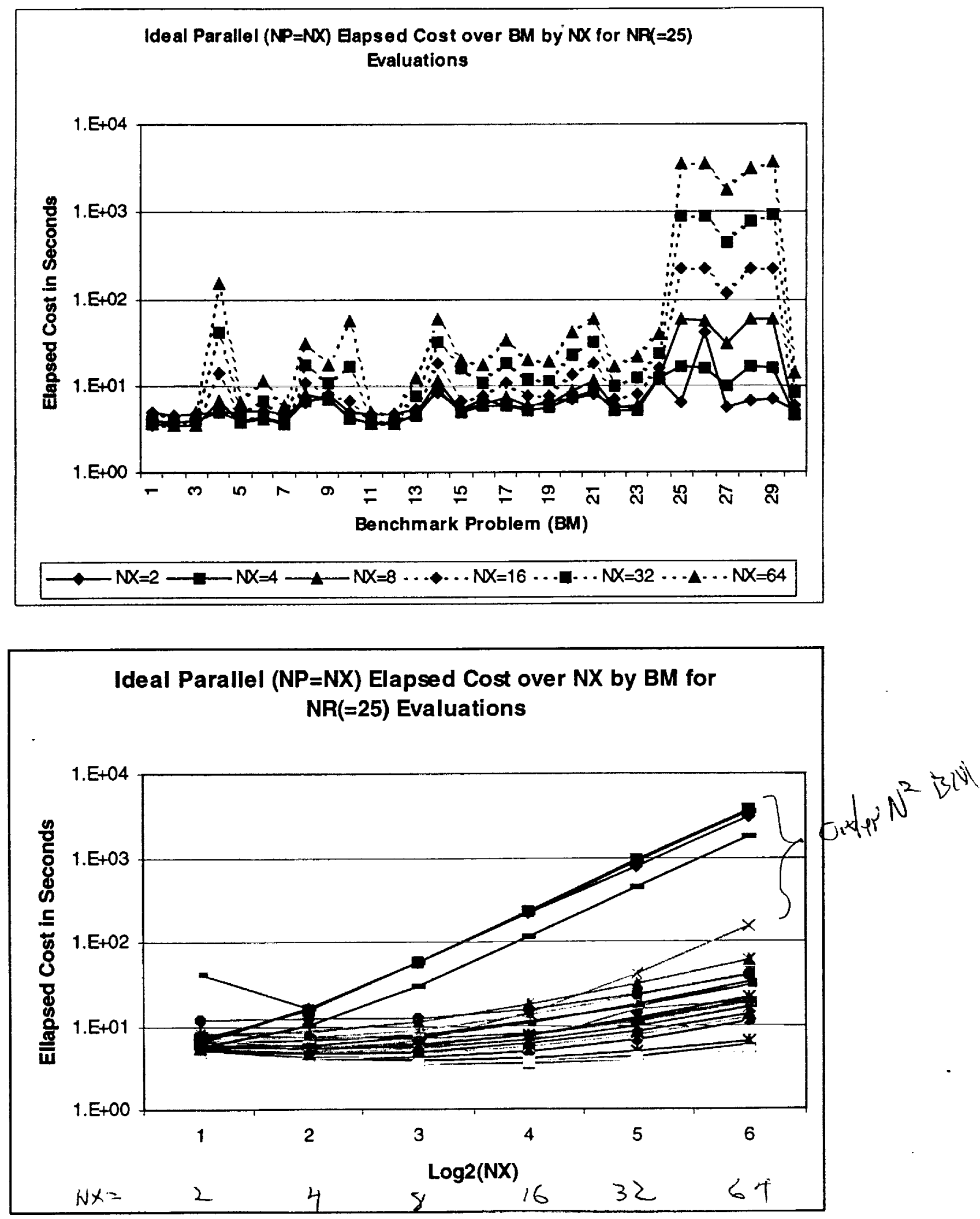


\section{Serial CPU Cost over NX for Selected BM for NP(=25) Evaluations}

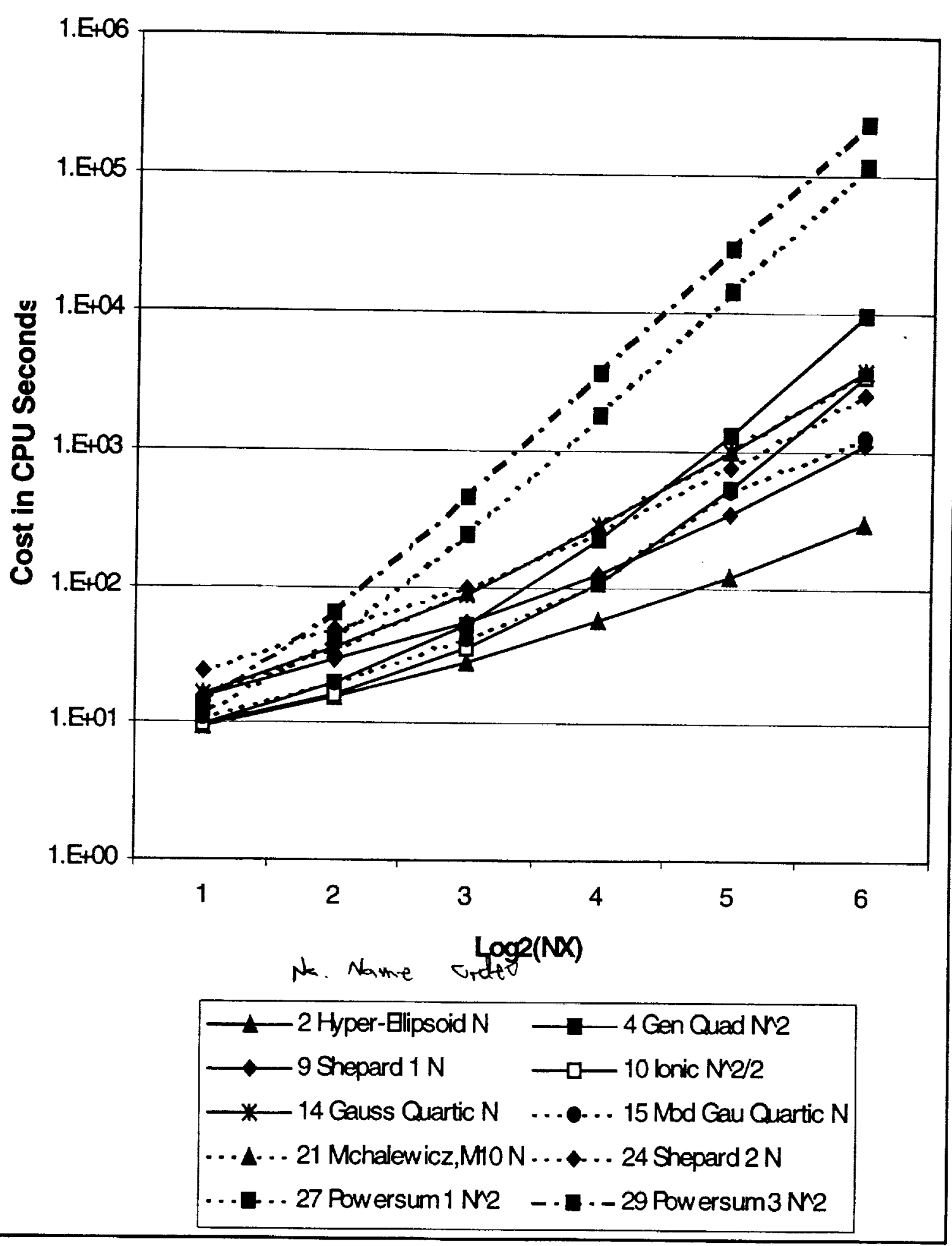




\section{Ideal Parallel (NP=NX) Eapsed Cost over NX for Selected BM for NR(=25) Evaluations}

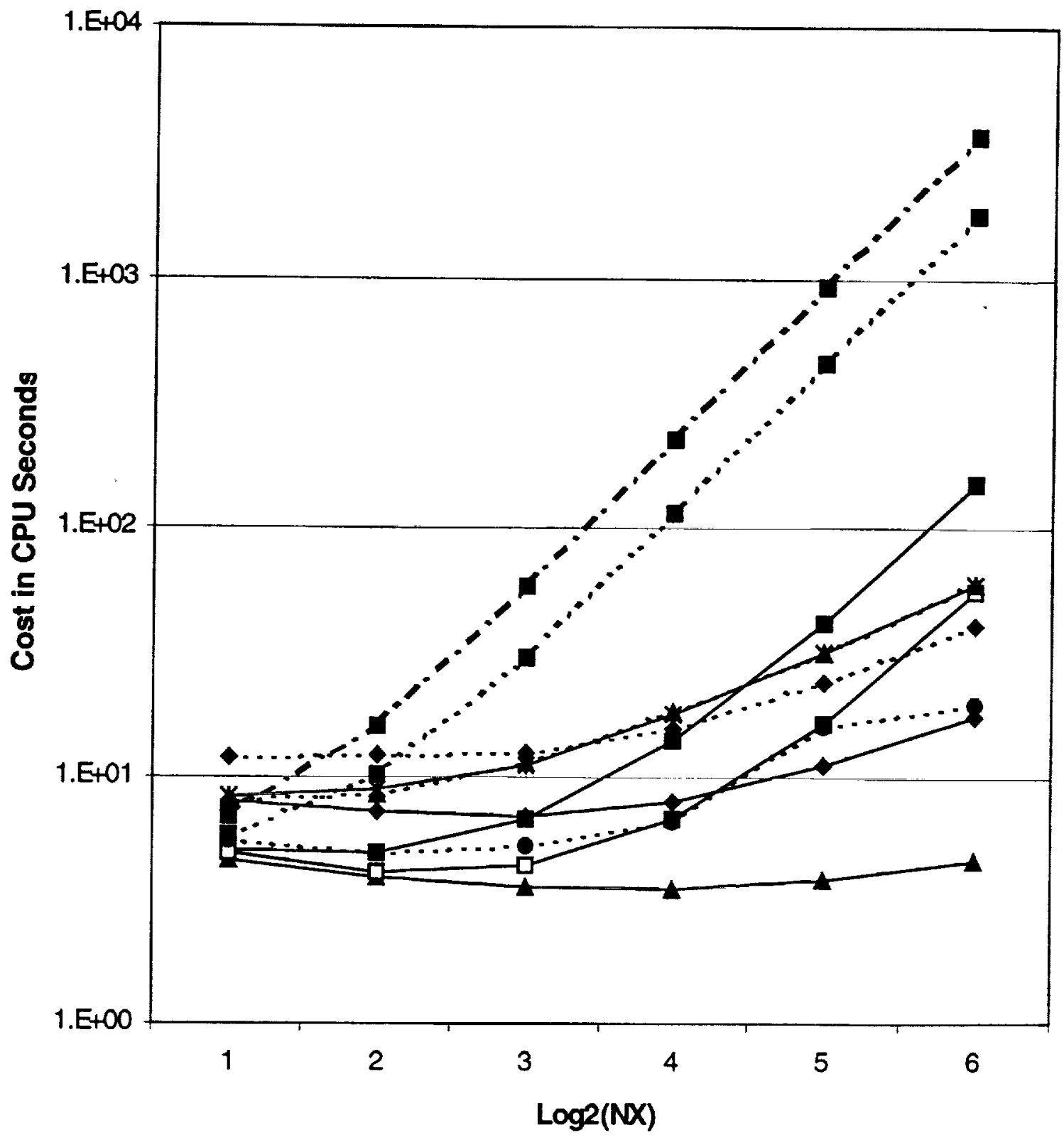

-2 Hyper-Blipsoid $N$

$\rightarrow-9$ Shepard $1 \mathrm{~N}$

- 14 Gauss Quatic $N$

... . . 21 Mchalew icz, MiO N

... . . 27 Pow ersum $1 \mathrm{~N} 2$

$\rightarrow-4$ Gen Quad N2

-10 lonic N2/2

... . . 15 Mod Gau Quartic N

... . 24 Shepard $2 \mathrm{~N}$

- - - - 29 Pow ersum 3 N2 


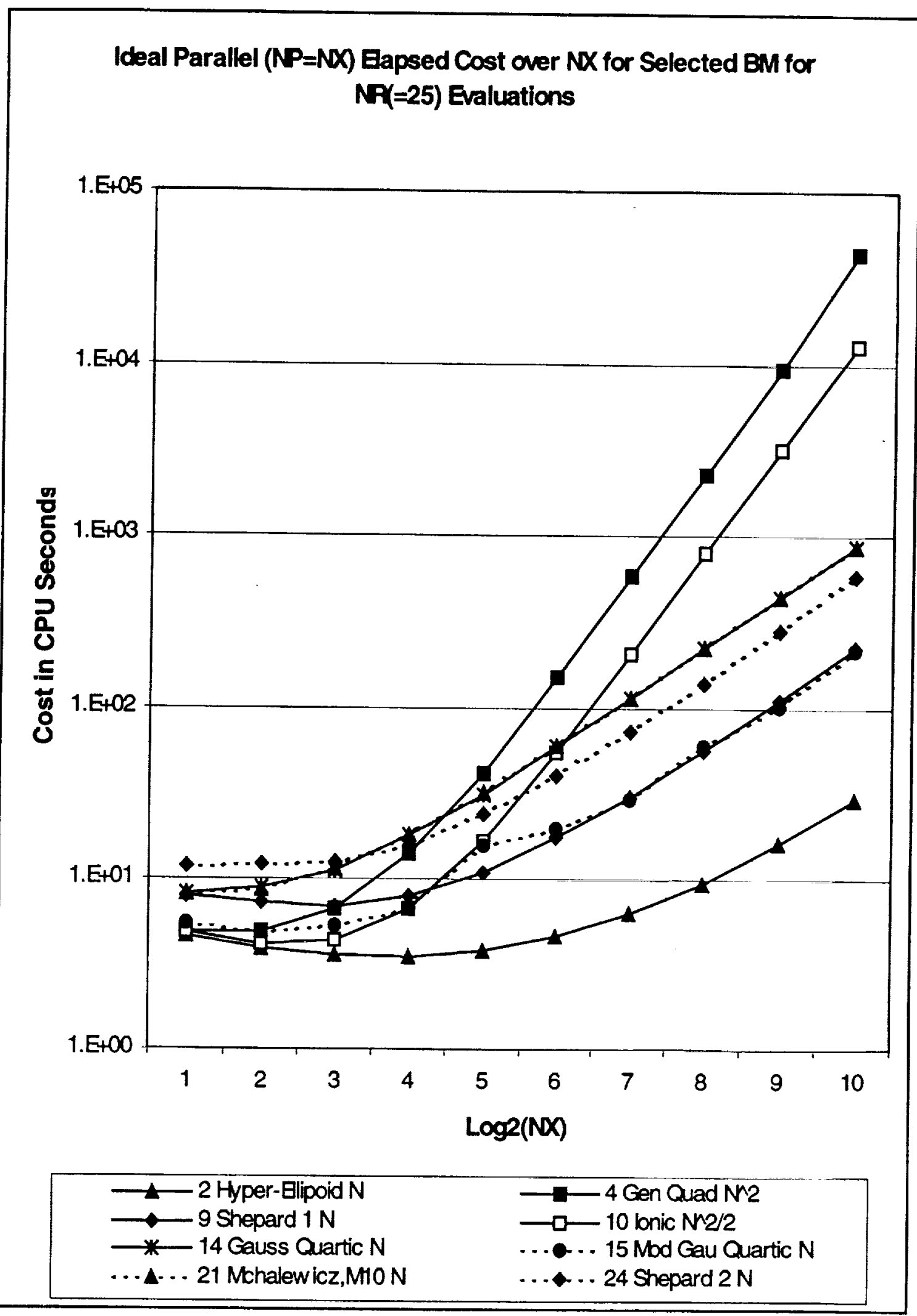

